\title{
Esophageal Squamous Cell Carcinoma with Marked Eosinophil Infiltration
}

\author{
Minoru Fukuchi ${ }^{a} \quad$ Shinji Sakurai ${ }^{b} \quad$ Masaki Suzuki \\ Hiroshi Naitoh $^{\mathrm{a}}$ Yuichi Tabe $^{\mathrm{a}}$ Takaharu Fukasawa $^{\mathrm{a}}$ \\ Shinsuke Kiriyama ${ }^{a}$ Takehiko Yokobori ${ }^{\mathrm{c}}$ \\ Hiroyuki Kuwanoc
}

Departments of a Surgery and ${ }^{b}$ Diagnostic Pathology, Social Insurance Gunma Chuo General Hospital, and 'Department of General Surgical Science, Gunma University Graduate School of Medicine, Maebashi, Japan

\section{Key Words}

Eosinophil infiltration - Esophageal squamous cell carcinoma - Esophagectomy

\begin{abstract}
We report a case of esophageal squamous cell carcinoma (SCC) with marked eosinophil infiltration which was identified postoperatively in the esophageal wall in areas not surrounding the SCC. The eosinophil infiltration was seen in the submucosa, muscle and adventitia, but not in the mucosa. Eosinophilic esophagitis (EoE) is a pathological condition defined as eosinophil infiltration within the esophageal mucosa. Eosinophil infiltration at the invasion front of esophageal SCC is termed tumor-associated tissue eosinophilia (TATE). However, the eosinophil infiltration in this case may be pathologically different from both EOE and TATE. To our knowledge, this is the first report of esophageal SCC with eosinophil infiltration.
\end{abstract}

\section{Introduction}

Eosinophilic gastroenteritis (EG) usually involves the stomach and small bowel, and esophageal involvement is rare [1]. EG is characterized by gastrointestinal symptoms, peripheral eosinophilia and eosinophil infiltration of the gastrointestinal tissues [2]. Although all layers of the stomach and bowel may be involved, symptoms usually reflect the layer which is most severely affected. Mucosal disease may be associated with malabsorption and protein deficiency, muscle disease with obstructive symptoms and serosal disease with eosinophilic ascites [3]. In addition, up to $50 \%$ of patients have 
other manifestations of allergy and there is usually a strong family history of allergy $[1,2]$. There is a uniformly successful response to steroid therapy.

Esophageal eosinophilia is a pathological condition defined as eosinophil infiltration within the esophageal mucosa, where eosinophils are not normally found [4]. This condition can have various causes, and primary or idiopathic esophageal eosinophilia is referred to as eosinophilic esophagitis (EoE). 5-58\% of patients with EoE are reported to show peripheral eosinophilia [5]. It has been reported that EoE is closely associated with allergic conditions, especially in the pediatric population. EoE has more recently been increasingly recognized in adults and is one of the most common causes of intermittent solid food dysphagia or food impaction in Western countries, but is rare in Asian countries [5, 6].

Squamous cell carcinoma (SCC) of the esophagus is one of the most common gastrointestinal malignancies in Japan and other Asian countries, and it is known to be an aggressive tumor. Recent studies have indicated that eosinophil infiltration at the invasion front of esophageal SCC may correlate with a less aggressive tumor [7, 8]. This type of eosinophil infiltration is termed tumor-associated tissue eosinophilia (TATE) [9]. However, the biological significance of TATE as a host response to carcinoma is not necessarily consistent.

We report a case of esophageal SCC with marked eosinophil infiltration. The resected esophageal wall showed eosinophil infiltration in areas not surrounding the SCC, which did not appear to be pathologically consistent with EoE or TATE.

\section{Case Report}

A 77-year-old Japanese man was admitted to our hospital for investigation and treatment of a superficial esophageal cancer, detected on upper gastrointestinal endoscopy in January 2011. The patient had a 4-week history of decreased appetite. He reported a 57-year history of drinking about $100 \mathrm{ml}$ of Japanese sake daily. There was no history of allergic disorder. A blood sample showed normal biochemistry and normal peripheral eosinophil count. Endoscopic examination showed the esophageal cancer as a slightly elevated lesion, 32-34 cm from the incisor teeth (fig. 1a). The tumor was reddish and almost granular in appearance. Iodine staining left the tumor unstained, but showed the margin more clearly (fig. 1b). A biopsy of the lesion showed poorly differentiated SCC without eosinophil infiltration. Computed tomography revealed a normal esophagus, but found lymphadenopathy of the right cardiac nodes. The stomach and bowel were normal. We performed an Ivor Lewis esophagectomy, consisting of a right thoracotomy and laparotomy with anastomosis in the chest, with two-field thoracoabdominal lymph node dissection. The enlarged right cardiac lymph node was found and dissected. Recovery was complicated by anastomotic leakage 3 days after surgery. The fluid collection around the anastomosis gradually drained through a drainage tube. The leakage improved over the 40 days following surgery, and the patient was discharged 75 days postoperatively.

The surgical specimens consisted of a $9 \mathrm{~cm}$ segment of esophagus with a $5 \mathrm{~cm}$ cuff of stomach and lymph nodes from the thoracic and upper abdominal groups. Gross examination confirmed a superficial esophageal cancer measuring $2.5 \times 2.5 \mathrm{~cm}$ (fig. 2) and did not show any other significant esophageal abnormality. The surgical specimens were fixed in $10 \%$ buffered formalin and embedded in paraffin. Paraffin sections were cut and stained with hematoxylin-eosin (H\&E). Microscopic examination revealed submucosal SCC with partial invasion into the middle layer (fig. $3 \mathrm{a}, \mathrm{H} \& \mathrm{E}, \times 20$ ). Metastatic disease was noted in one of the right cardiac lymph nodes. There was also marked eosinophil infiltration of the full length of the esophageal wall except around the SCC (more than 100 eosinophils per high-power field) (fig. $3 f, H \& E, \times 400$ ). Eosinophil infiltration was seen in the 
submucosa, muscle and adventitia, but not in the mucosa (fig. 3b, H\&E, $\times 20$; fig. 3c, d, e, H\&E, ×100). Mild eosinophil infiltration was also seen in the same layers of the upper stomach.

\section{Discussion}

EG is an uncommon disease characterized by peripheral eosinophilia and eosinophil infiltration of the gastrointestinal tract [2]. The most common sites affected are the stomach and small bowel, and esophageal involvement is rare [1]. The clinical presentation depends on the site of gastrointestinal tract involvement as well as the layer of the bowel wall that has been infiltrated. EG has been classified into three types according to the predominant location of eosinophil infiltration: mucosal, muscular and subserosal [3]. EoE is diagnosed by eosinophil infiltration within the esophageal mucosa only [4]. Eosinophil infiltration at the invasion front of SCC is termed TATE and correlates with tumor progression $[7,8]$.

In our case, eosinophil infiltration was seen in the submucosa, muscle and adventitia of the entire esophageal wall except around the SCC, and there was no peripheral eosinophilia. Pathologically, the eosinophil infiltration in this case appeared to be more similar to predominantly muscular or subserosal EG than to EoE or TATE. The patient did not, however, have stenosis or obstruction as typically associated with muscular disease, or pleural effusion as typically associated with subserosal disease. His only symptom was loss of appetite, but it is unknown whether that was related to the eosinophil infiltration or to the esophageal SCC.

Landres et al. [10] have previously reported a case of achalasia with esophageal eosinophilia that underwent esophageal myotomy revealing eosinophil infiltration of the muscle layer. Preoperative endoscopic biopsy revealed chronic inflammation of the esophageal mucosa. The patient had experienced epigastric pain, but became asymptomatic following esophageal myotomy. Some reports have described that eosinophil infiltration of the muscle layers of the esophagus appeared to be related to esophageal narrowing, although no pathological diagnosis was recognized. Steroid therapy was required for severe cases of esophageal narrowing [11-15].

Eosinophil infiltration was diagnosed in our case only after resection of the esophageal SCC. As there was no eosinophil infiltration in the mucosa or around the SCC, it would have been difficult to diagnose this by preoperative biopsy. Gross examination of the surgical specimen did not show the eosinophil infiltration, which was revealed only by microscopic examination. Our case was also complicated by postoperative leakage of the anastomosis. If the eosinophil infiltration promoted inflammation of the esophagus, this may have been a risk factor for the leakage. However, the significance of eosinophil infiltration in the esophageal wall remains unclear.

To the best of our knowledge, we report the first case of esophageal SCC with marked eosinophil infiltration. The diagnosis was made only after esophagectomy, but eosinophil infiltration such as in this case is pathologically significant. Eosinophil infiltration of the esophagus may represent a variant of EG and may predispose to postoperative complications $[1,10]$. 


\begin{tabular}{r|l|l|l}
$\begin{array}{r}\text { Case Reports in } \\
\text { Gastroenterology }\end{array}$ & $\begin{array}{l}\text { Case Rep Gastroenterol 2011;5:648-653 } \\
\text { DOI: 10.1159/000332441 }\end{array}$ & $\begin{array}{l}\text { Published online: } \\
\text { November 30, 2011 }\end{array}$ & $\begin{array}{l}\text { @ 2011 S. Karger AG, Basel } \\
\text { ISSN 1662-0631 } \\
\text { www.karger.com/crg }\end{array}$ \\
\hline
\end{tabular}

\section{Disclosure Statement}

The authors have no conflicts of interest.
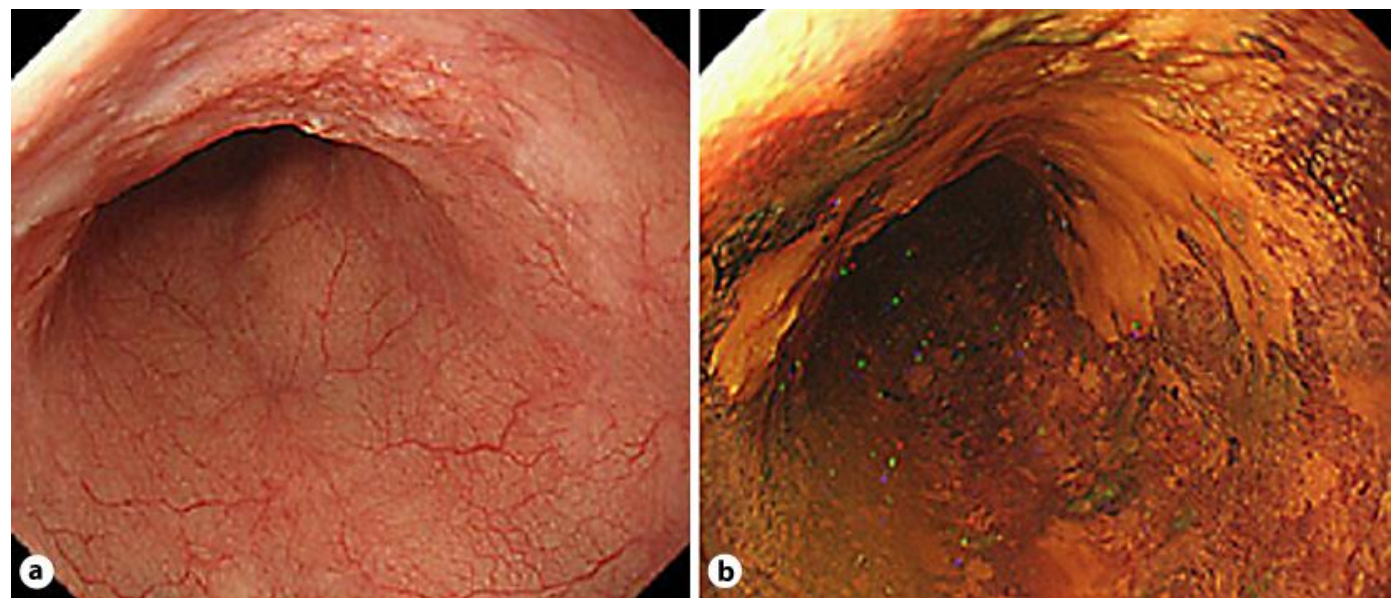

Fig. 1. Endoscopic examination. a An elevated, granular lesion is shown $32-34 \mathrm{~cm}$ from the incisor teeth. $\mathbf{b}$ Iodine staining left the tumor unstained, but the tumor margins became clearer.

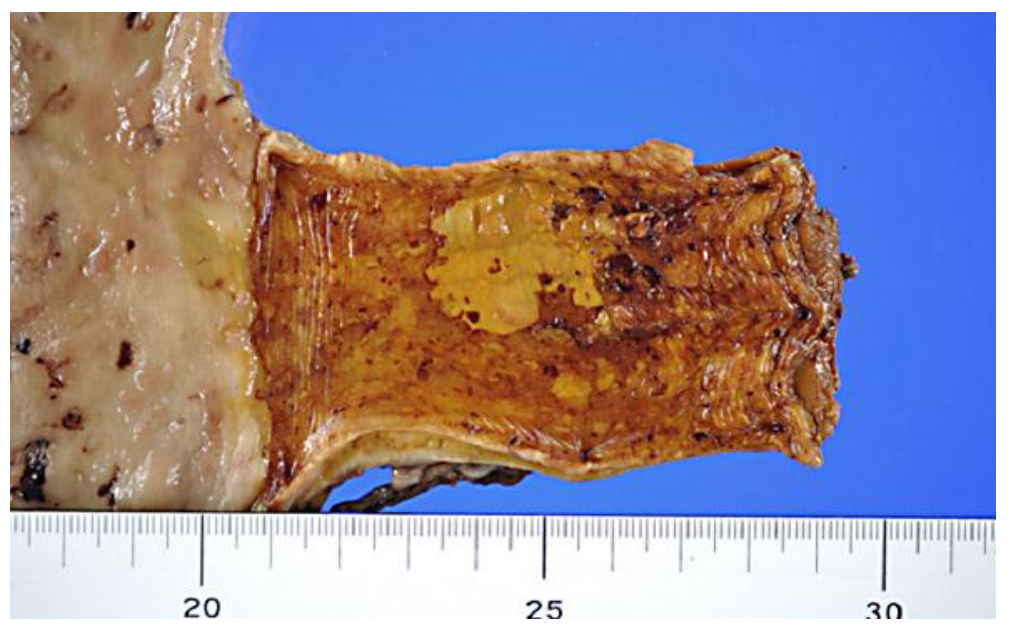

Fig. 2. Surgical specimens. The SCC $(2.5 \times 2.5 \mathrm{~cm})$ was not stained with iodine. The rest of the esophageal wall was normal in appearance. 


\begin{tabular}{|c|c|c|c|}
\hline $\begin{array}{l}\text { Case Reports in } \\
\text { astroenterology }\end{array}$ & $\begin{array}{l}\text { Case Rep Gastroenterol 2011;5:648-653 } \\
\text { DOI: 10.1159/000332441 }\end{array}$ & \begin{tabular}{|l|} 
Published online: \\
November 30, 2011
\end{tabular} & $\begin{array}{l}\text { (c) } 2011 \text { S. Karger AG, Basel } \\
\text { ISSN } 1662-0631 \\
\text { www.karger.com/crg }\end{array}$ \\
\hline
\end{tabular}
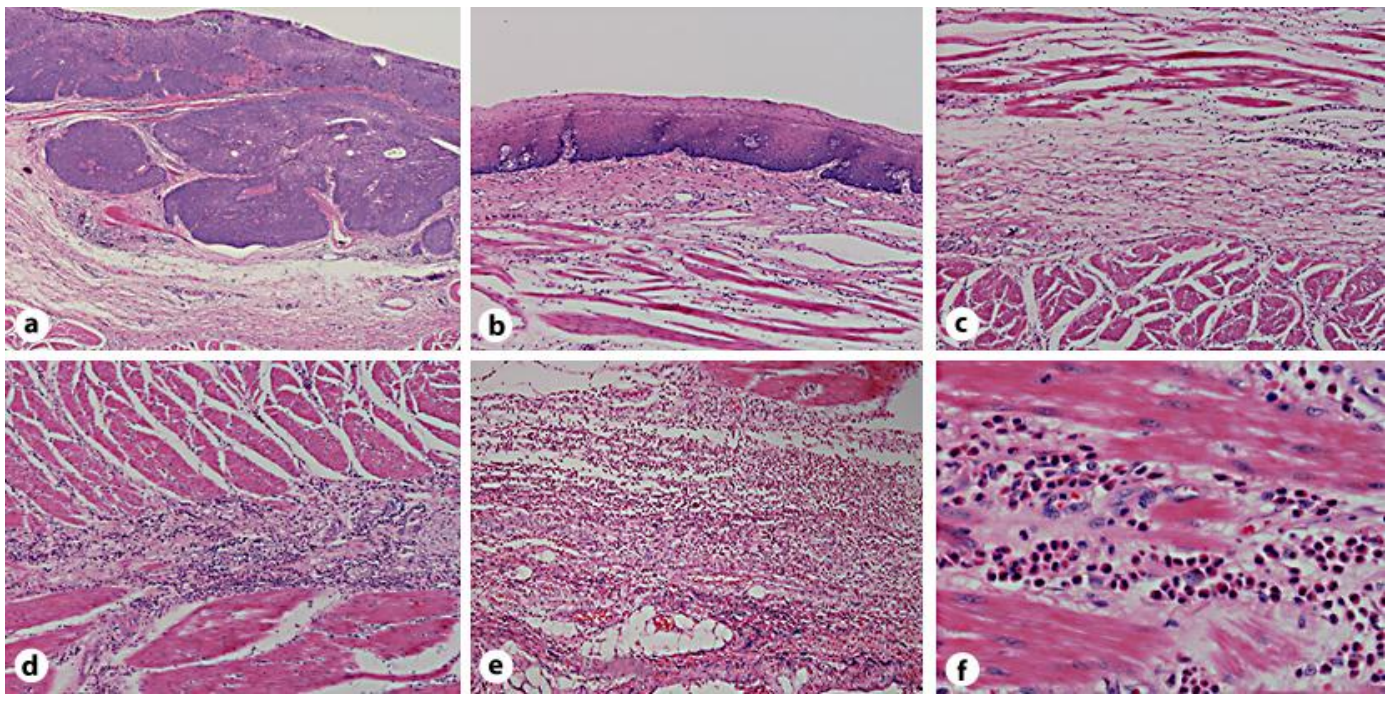

Fig. 3. Microscopic examination. a The SCC had partially invaded the middle layer $(\mathrm{H} \& \mathrm{E}, \times 20)$. Eosinophil infiltration was not seen around the SCC. b-e There was eosinophil infiltration of the full length of the esophageal wall except around the SCC. Eosinophil infiltration was not seen in the mucosa (b, H\&E, × 20), but was marked in the muscle, submucosa and adventitia (c, d, e, H\&E, ×100). f There was eosinophil infiltration of the muscle layer with more than 100 eosinophils per high-power field (H\&E, ×400).

\section{References}

1 Liacouras CA, Markowitz JE: Eosinophilic esophagitis: a subset of eosinophilic gastroenteritis. Curr Gastroenterol Rep 1999;1:253-258.

-2 Talley NJ, Shorter RG, Phillips SF, Zinsmeister AR: Eosinophilic gastroenteritis: a clinicopathological study of patients with disease of the mucosa, muscle layer, and subserosal tissues. Gut 1990;31:54-58.

-3 Klein NC, Hargrove RL, Sleisenger MH, Jeffries GH: Eosinophilic gastroenteritis. Medicine 1970;49: 299-319.

4 Rothenberg ME, Hogan SP: The eosinophil. Annu Rev Immunol 2006;24:147-174.

5 Furuta K, Adachi K, Kowari K, Mishima Y, Imaoka H, Kadota C, Koshino K, Miyake T, Kadowaki Y, Furuta K, Kazumori H, Sato S, Ishihara S, Amano Y, Honda M, Kinoshita Y: A Japanese case of eosinophilic esophagitis. J Gastroenterol 2006;41:706-710.

6 Abe Y, Iijima K, Ohara S, Koike T, Ara N, Uno K, Asano N, Imatani A, Kato K, Shibuya D, Shimosegawa T: A Japanese case series of 12 patients with esophageal eosinophilia. J Gastroenterol 2011;46:25-30.

-7 Ohashi Y, Ishibashi S, Suzuki T, Shineha R, Moriya T, Satomi S, Sasano H: Significance of tumor associated tissue eosinophilia and other inflammatory cell infiltrate in early esophageal squamous cell carcinoma. Anticancer Res 2000;20:3025-3030.

-8 Ishibashi S, Ohashi Y, Suzuki T, Miyazaki S, Moriya T, Satomi S, Sasano H: Tumor-associated tissue eosinophilia in human esophageal squamous cell carcinoma. Anticancer Res 2006;26:1419-1424.

-9 Lowe D, Jorizzo J, Hutt MS: Tumour-associated eosinophilia: a review. J Clin Pathol 1981;34:1343-1348.

10 Landres RT, Kuster GG, Strum WB: Eosinophilic esophagitis in a patient with vigorous achalasia. Gastroenterology 1978;74:1298-1301.

11 Dobbins JW, Sheahan DG, Behar J: Eosinophilic gastroenteritis with esophageal involvement. Gastroenterology 1977;72:1312-1316. 
12 Picus D, Frank PH: Eosinophilic esophagitis. AJR Am J Roentgenol 1981;136:1001-1006.

-13 Matzinger MA, Daneman A: Esophageal involvement in eosinophilic gastroenteritis. Pediatr Radiol 1983;13:35-38.

14 Feczko PJ, Halpert RD, Zonca M: Radiographic abnormalities in eosinophilic esophagitis. Gastrointest Radiol 1985;10:321-324.

15 Minematsu H, Hayafuji K, Saito Y, Ogawa A, Nakahara T, Hata K, Tsujikawa T, Andoh A, Fujiyama Y, Kushima R: A case of esophagitis with pleural effusion. Gastroenterol Endosc 2009;51:194-200. 